\title{
Immunochemical determination of xenobiotics with endocrine disrupting effects
}

\author{
M.-C. Estévez-Alberola ${ }^{1}$ and M.-P. Marco ${ }^{1}$ \\ (1) Department of Biological Organic Chemistry, IIQAB-CSIC, Jordi Girona, 18-26, \\ 08034 Barcelona, Spain
}

M.-P. Marco Email: mpmqob@iiqab.csic.es

\begin{abstract}
This paper is a review with more than 100 references discussing the immunochemical methods reported in the literature for the most important man-made chemicals with suspected endocrine disrupting activity. Details regarding immunizing hapten design, antibody production, and the features (limit of detection, dynamic range, specificity) of the most important immunochemical methods developed (ELISA, FIIA, immunosorbents, immunosensors, etc.) are presented for important environmental pollutants such as bisphenol A, phthalates, alkylphenol polyethoxylates, alkylphenols, polychlorinated biphenyl compounds, and dioxins. Availability of commercial reagents and methods is reported.
\end{abstract}

Keywords Immunochemical techniques - Endocrine disruptors - Alkylphenols Phthalates - Bisphenol A - Dioxins

\section{Introduction}

During recent decades much attention has been concentrated in the study of the health effects and risk assessment of many natural and synthetic substances in wildlife and humans. In particular, great concern has been focused on certain man-made substances that are capable of interaction with the estrogen receptor, induce a biological response, and cause a disruption in the endocrine system of animal and human organisms (for reviews see refs. $[1,2,3,4,5,6,7,8,9])$. The endocrine system is responsible for practically all the important functions in the organisms such as sexual differentiation, sexual maturation during puberty, growth reproduction, and behavior, and it is controlled by hormones. Besides the natural substances (like estrogens, progesterone, and testosterone in humans and animals or the phytoestrogens in some plants) there are a large number of synthetic compounds known as endocrine disruptors chemicals (EDCs) that can interact in different ways with the endocrine system. Mechanisms of action include mimicking or antagonizing the effect of endogenous hormones, interfering in the production and metabolism of endogenous hormones, or disrupting the synthesis of hormone receptors. Some of these compounds are synthetic hormones (e.g., ethynylestradiol, synthetic androgenic substances, etc.) produced to specifically interact with the hormonal receptor (contraceptive pill, growth-promoters used for meat production, etc.). However, most of them are man-made chemicals of industrial origin, with diverse chemical structures and are produced with different purposes far away from the endocrine action. Some others are by-products of industrial processes (e.g., dioxins). These substances are generating great concern within the public and scientific community $[10,11]$. In the final report of the European Commission towards the 
establishment of a priority list of EDCs [12], from 564 suspected substances, 146 were selected because of their persistence or high production volume. From these, 66 substances ( 35 chemical groups) were categorized into category 1 (at least one study provides evidence of endocrine disruption in an intact organism) and 60 substances (29 chemical groups) were considered to be of high human and wildlife exposure concern. These include substances such as some pesticides (maneb, metam, zineb, etc.), polychlorinated biphenyls (PCBs), dichlorodiphenyltrichloroethane (DDT), dioxins (PCDDs), and furans (PCDFs), polybrominated diphenyl ethers (PBDE), alkylphenolic compounds such as octylphenol (OP), nonylphenol (NP) and their short-chain ethoxylated derivatives (APEs), phthalate esters (PE), and bisphenol A (BPA).

The type of endocrine disrupting activities reported for these substances are effects in the uterus, testes, prostate, or other sex organ weights, in sperm development, vaginal opening, thyroid hormone levels, and neuroendocrine pituitary effects. Although the hormonal effects of most of them are weak (the estrogenic activity it ranges from $1 / 1,000$ th to $1 / 11,000,000$ th compared with estradiol), many effects have been observed in wildlife species exposed to these chemicals, such as an abnormal development of the reproductive organs and reproductive disorders in fish. Moreover, an increase of the incidence of testicular and prostate cancers in males and breast cancer and endometriosis in females has been suggested to be related to an exposure to these substances $[9,13]$. Another important consideration that must be taken into account is the presence of multicomponent mixtures of xenoestrogens. Although it seems that synergisms are not produced, the additive combination effects of these EDCs have been observed at individual concentrations which are lower than their no observed effect concentration value (NOEC)[14].

All evidence observed during recent years raises the need for a continuous development of effective methods for risk and environmental assessment of these substances. Specific and sensitive techniques for the detection of EDCs in environmental samples are required to increase environmental monitoring efficiency and to protect public health from the adverse effects that potentially may result. The key requirements for environmental monitoring and analysis are the limit of detection and the selectivity but also other aspects such as time per sample analysis, sample pretreatment requirements, the cost of equipment and maintenance, and the operator skills.

Analytical tools based on conventional techniques such as gas or liquid chromatography (GC and LC) coupled to sensitive detection systems such as mass spectrometry (MS) or MS-MS have been applied to detect EDCs. Unfortunately, most of these techniques are time-consuming and have elevated cost due to the fact that extensive clean-up and sample treatment methods that often involve derivatization procedures are required. Alternatively, immunochemical techniques offers a large number of advantages, the most relevant being the selectivity and sensitivity shown by the specific antibodies for the target analyte, the use of small sample volumes, the low cost, and the simplicity of the methodologies. Moreover, they are easily adapted to automated systems and to development of high-throughput screening (HTS) methods. In this paper a review of the immunochemical methods developed for the determination of man-made EDCs in environmental samples is reported. For analytical methods used to determine natural or synthetic steroids hormones the reader is referred to other published literature $[15,16]$. A variety of immunochemical methods against those hormones have also been reported $[17,18,19,20,21,22,23]$ and several antibodies (both monoclonal and polyclonal) and 
immunoassay kits are commercially available. Therefore, only those substances from industrial origin will be treated in this paper. A short introduction to the most common immunochemical techniques applied for environmental monitoring will be presented initially. Particular attention has been paid to immunochemical methods reported for those EDCs rated as high to medium risk of exposure for the human and wildlife population, as occurs with APEs, PE, BPA, PCBs, PCDDs and PCDFs. We will not go through the immunochemical determination of pesticides with suspicious ED activity, since the reader may find other reviews dealing with this topic $[21,24,25,26,27]$.

\section{Immunochemical methods}

Immunochemical techniques are based on the specific interaction between antibodies and antigens. Although the principles of the immunological reaction are not new, there has been important progress in the development of these methodologies in recent years owing to the availability of antibodies for a great variety of foreign low-molecularweight molecules, macromolecules, drugs, and proteins. Small molecules themselves are generally not capable of stimulating the immune response in the host animal. Therefore, synthesis of an analogue of the target analyte (the immunizing hapten) is required in order to conjugate it to a carrier protein. The choice of a suitable hapten, which should keep the most characteristic groups of the analyte without altering, as far as possible, their electronic and geometric features, is the key step in the production of good antibodies [28]. During recent years specific antibodies have been obtained for a large variety of pesticides, xenobiotics, and other kinds of environmental pollutants, and innovative immunochemical approaches have been developed based on the $\mathrm{Ab}-\mathrm{Ag}$ reaction $[29,30]$. The more relevant ones are briefly detailed below.

\section{Immunoassays}

The most widely used immunochemical method for pollutant detection is the immunoassay (IA) $[31,32,33,34]$. This method is based on the use of labels to detect the reaction $\mathrm{Ab}-\mathrm{Ag}$. These assays can be run in homogeneous or heterogeneous formats. In the former, all the immunoreagents are in solution, and there is no separation between the free $(\mathrm{Ag}$ and $\mathrm{Ab})$ and the bound phase $(\mathrm{Ag}-\mathrm{Ab}$-labeled and nonlabeled) before the detection step. In the heterogeneous format, one of the immunoreagents is immobilized on a solid support, which facilitates the isolation of the bound fraction $(\mathrm{Ag}-\mathrm{Ab})$. Homogeneous formats are often less sensitive but the simplicity of the format makes them very useful for applications in process monitoring. Several markers such as chemiluminescent or fluorescent molecules are used as labels, and novel techniques have emerged such as the competitive binding chemiluminescent immunoassay (CLIA), competitive binding fluoroimmunoassays (FIA), time-resolved fluroimmunoassay (TRFIA), and polarization fluorescent immunoassay (PFIA). Most of these operate in homogeneous formats. However, the most common labels are still enzymes, the most frequently used being horseradish peroxidase (HRP) and alkaline phosphatase (AP). Within these enzyme immunoassays (EIAs), the heterogeneous format is the most common and it is referred to as enzyme-linked immunosorbent assays (ELISAs). When the analytes are small molecules the immunoassays must work under competitive configurations. A competition takes place between a free antigen (or analyte, Ag) and a labeled $\mathrm{Ag}\left(\mathrm{Ag}^{*}\right)$ for a fixed and limited amount of specific Ab. At the final step, the 
amount of labeled Ag can be measured, and subsequently, the free Ag. A short description of the most common immunoassay formats employed for environmental analysis is presented below.

\section{Fluoroimmunoassays (FIAs) and chemiluminescent immunoassay (CLIAs)}

Several FIAs and CLIAs have been developed for detection of environmental pollutants $[35,36,37]$. Fluorescent labels such as fluorescein, rhodamine, $\mathrm{Eu}(\mathrm{III}), \mathrm{Tb}(\mathrm{III})$, and $\mathrm{Sm}$ (III) chelates, or chemiluminescent substances such as luminol are used in these immunoassays . In FIAs, the sensitivity may be limited by the background noise of some samples. Often the fluorophore is generated enzymatically rather than using it directly in order to improve sensitivity by taking advantage of the enzyme turnover. FIAs have often been adapted to flow-immunoassays systems (FIIA) in which the assay takes place on small reactors to which samples and reagents (antibodies, labeled antigens, etc.) are delivered in an automated mode (see below).

\section{Polarization fluorescent immunoassays (PFIAs)}

These homogeneous immunoassays are based on the difference in a rotational movement between the bound and the free labeled antigen (tracer). When a specific antibody binds a fluorophore-labeled hapten, an increase in fluorescent polarization is observed. Similarly, the signal decreases when the free analyte competes for binding to the Ab. Usually these assays are less sensitive than EIAs but are very useful for sample screening $[38,39,40]$.

\section{Enzyme-linked immunosorbent assay (ELISA)}

These heterogeneous assays can be found on a great variety of modes and formats. ELISAs have been described that are performed in tubes, plastic-baked nitrocellulose membranes, magnetic particles, etc., but most often 96-well microtiter plates are preferred since these allow the simultaneous analysis of a large number of samples. Depending on the immunoreagent immobilized on the plate, two main formats can be distinguished when small molecules are analyzed: the direct and indirect. In the direct format, the $\mathrm{Ab}$ is usually coated on the active surface and equilibrium is established between the analyte and the enzyme tracer for binding to the Ab. The unbound reagents are washed away and the amount of tracer is measured. The enzyme activity is inversely proportional to the amount of analyte present. In the indirect format the $\mathrm{Ag}$ is immobilized and the amount of analyte is indirectly measured by the quantification of the bound $\mathrm{Ab}$ with a second labeled $\mathrm{Ab}$. There are examples of ELISA for a large number of pollutants, such as carbamates, organochlorine and organophosphorous compounds, triazines, PAHs, PCBs, etc. [33].

\section{Flow-injection immunoassays (FIIA)}

Flow-injection immunoassays systems (FIIA) [41, 42, 43] offer an interesting alternative to classical immunoassay by combining the immunochemical principles with the flow-injection methodologies. The automation of the technique allows the screening of a large number of samples and real-time monitoring data, often without any lost of 
the detectability accomplished by a traditional ELISA method. In these assays the sample is incorporated in a carrier stream which enters in a reactor chamber where the immunological reaction takes place. Some FIIAs have been developed for the analysis of several pollutants such as pesticides $[41,44,45,46]$ and other industrial pollutants such as PCBs [47], thereby demonstrating that FIIAs can be more precise and rapid than an ELISA offering automation with low cost.

\section{Immunoaffinity chromatography}

Immunoaffinity chromatography (IAC) $[48,49]$ combines the immunochemical reaction $\mathrm{Ab}-\mathrm{Ag}$ with solid-phase extraction techniques. The specific $\mathrm{Ab}$ is covalently immobilized on an activated solid support (usually agarose, polyacrylamide, polyacrylic, etc.) and is then packed in small cartridges. These columns specifically retain the target analyte. The non-specifically bound compounds are removed and the analyte can then be eluted when appropriate desorption conditions have been found and optimized (usually introducing changes in the buffer composition, such as the $\mathrm{pH}$, the ionic strength, and the ratio of organic solvent). This technique can be used as a clean-up pretreatment to remove the interferences. These substances can cause possible matrix effects when complex environmental samples are analyzed off-line with conventional methods such as HPLC, GC, or even with IAs (immunoassays). Some examples of this application can be found in the literature for some pesticides [50, 51, 52, 53, 54].

\section{Immunosensors}

There are several kinds of biosensor depending on the biological recognition element (i.e., enzymes, whole cells, receptors, DNA, etc.) and the transducing principle employed (piezoelectric, electrochemical, thermistor, or optical $[55,56,57,58]$ ). On immunosensors the biological component can be either a specific antibody or the antigen. The biomolecule is immobilized on a physical transducer capable of transforming the physicochemical changes (dielectric constant, weight, charge, $\mathrm{pH}$, etc.) produced when the immunoreaction $\mathrm{Ag}-\mathrm{Ab}$ takes place on the active surface into a measurable electrical signal. The current requirements needed for the analysis of trace substances and pharmaceuticals in food industries and in clinical areas [59] have made of the immunosensors interesting alternatives that may provide fast, highly sensitive, specific, and automated analytical devices, continuous monitoring systems, etc. Although the most well known of these is the glucose sensor and other sensors employed for medical diagnoses, several immunosensors have also been developed for the detection of pesticides $[60,61,62]$ and pollutants $[63,64]$.

\section{Immunochemical methods for EDC analysis}

In the following sections, the most important chemical groups from industrial origin with demonstrated estrogenic effects will be presented and discussed in terms of published immunochemical methods available today.

\section{Alkylphenolic compounds}


Within the nonionic surfactants, the most important one is the group of alkylphenol polyethoxylates (APEs). They have been widely used in detergent formulations, both domestic and industrial, for many years. Other areas where these surfactants have been applied comprise the pulp and paper industry, pesticide formulations, in the leather and fur industry, and in the area of pharmaceutical and personal care products (PPCPs). The most common APEs are those produced from nonylphenol (nonylphenol polyethoxylates, NPEs) and octylphenol (octylphenol polyethoxylates, OPEs). Alkylphenols themselves have also been used as plasticizers and stabilizers in plastics. Worldwide production is about 500,000 $\mathrm{t}$ [65], which represents $8 \%$ of the total production of surfactants used in the USA, Japan, and Western Europe [66]. This considerable consumption of these nonionic surfactants involves great levels of discharges of APEs into the environment. In the wastewater treatment plants (WWTPs) the APEs are readily biodegraded under both aerobic and anaerobic conditions [67] losing most of the ethoxylate units; the final breakdown products are APEs with one or two ethoxylate groups (AP1EO, AP2EO), alkylphenoxy carboxylic acid (APEC), and APs. These products have lost their surfactant properties and can persist for longer time in the environment. The more polar APECs can persist in wastewater, effluents, and rivers. APs and short-chain APEs are more lipophilic and persist mainly in soils, sediments, and sludge $[68,69,70]$.

Whilst long-chain APEs seem to present low toxicity in organisms, APs, both OP and NP, have been revealed as much more toxic with a demonstrated estrogenic effect [71, $72,73]$. The environmental levels of these compounds may exceed the predicted no effect concentration (PNEC) of $0.33 \mu \mathrm{g} \mathrm{L}{ }^{-1}$ [68] proposed in a risk assessment report to the European Union. Although disagreements were previously observed over risks of these surfactants, nowadays, several regulatory measures have been taken both in Europe and USA. For instance many European countries have banned the use of APs in domestic applications and APEs have been substituted for less toxic surfactants such as alcohol ethoxylates (AEs). In the USA, serious regulatory actions are now being taken into account related to domestic use of APEs.

This current increasing concern has led to the development of specific, sensitive, and rapid techniques for their detection. Many conventional methods based on HPLC and GC coupled to a MS detector have been optimized to give good levels of sensitivity [74, 75 ] in the range of $n g \mathrm{~L}^{-1}$.

\section{Immunochemical techniques for APEs and APs}

Few references have been found in the literature related to specific antibodies against APEs. Goda et al. [76, 77] reported the production of monoclonal antibodies recognizing both APEs and APs (NP and OP) to the same extent. The chosen immunizing hapten retained the alkyl chain (the nonyl chain) intact and was derivatized keeping five ethoxylates groups (EO) in the molecule (see hapten 1A in Scheme 1). A microtiter plate direct ELISA was developed. Preparation of the antibody-coated plate involved several steps including two overnight blocking steps and the competitive assay was then run in $90 \mathrm{~min}$. The sensitivity obtained for NP is not extremely good, with a limit of detection (LOD) of $10 \mu \mathrm{g} \mathrm{L}^{-1}$ (see Table 1). Long- $(\mathrm{EO}=10)$, medium- $(\mathrm{EO}=5-$ 7 ), and short-chain $(\mathrm{EO}=1,2)$ APEs and APs (both NP and OP) are also well recognized. This lack of specificity has the disadvantage that overestimated values are obtained when the estrogenic NP levels are determined; however, it can be useful as a screening 
method. This assay and the monoclonal antibodies have been commercialized by Takeda Industries (Japan) [78]. The ELISA kit specifications indicate that APECs (NP2EC, NP3EC) are highly recognized (near 400\% considering NP as 100\%). These results are consistent, since the immunizing hapten is in essence a NPEC. This company has also developed another monoclonal antibody specific only for APEs with more than two ethoxylate units; AP, AP1EO, and AP2EO are not recognized [78]. The working range is similar to that obtained in the aforementioned case (see Table 1). In both cases other relevant surfactants such as linear alkylbenzene sulfonates (LAS), which could interfere in environmental samples from wastewater or effluents, are not recognized. Thus, the combination of both assays allows the determination of total concentration of these last three metabolites of APEs.<smiles>CCCCCCCCCCOc1ccc(CCOC(=O)C(C)C)cc1</smiles>

$1 \mathrm{~A}$

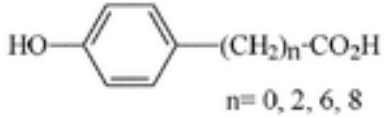

$1 \mathrm{~B}$

Scheme 1A,B Chemical structures of the immunizing haptens used to raise antibodies for APEs and AP. A Hapten used by Goda et al. [76] to obtain monoclonal antibodies. B Hapten used by Franek et al. [79] to obtain polyclonal antibodies

Table 1 Immunochemical techniques developed for the detection of APEs and AP

\begin{tabular}{|c|c|c|c|c|c|}
\hline Compound & $\begin{array}{l}\text { Immunochemical } \\
\text { technique }\end{array}$ & $\begin{array}{l}\mathrm{LOD}^{\mathrm{a}} / \mathrm{IC}_{50}{ }^{\mathrm{b}} \\
\left(\mu \mathrm{g} \mathrm{L} \mathbf{L}^{-1}\right)\end{array}$ & $\begin{array}{l}\text { Working range } \\
\left(\mu \mathrm{g} \mathrm{L}^{-1}\right)\end{array}$ & Comments & Ref \\
\hline NP & Direct ELISA & $10^{\mathrm{a}}$ & $70-1,000$ & $\begin{array}{l}\text { Monoclonal Ab Both APEs and } \\
\text { APs are well recognized }\end{array}$ & {$[76]$} \\
\hline NP & $\begin{array}{l}\text { Commercial Direct } \\
\text { ELISA Kit }\end{array}$ & $n r^{c}$ & $5-500$ & $\begin{array}{l}\text { Monoclonal Ab OP, NPEs, OPEs, } \\
\text { and NPECs are strongly } \\
\text { recognized }\end{array}$ & [78] \\
\hline APEs & $\begin{array}{l}\text { Commercial Direct } \\
\text { ELISA Kit }\end{array}$ & $\mathrm{nr}$ & $50-2,000$ & $\begin{array}{l}\text { Monoclonal Ab APEs with EO } \\
\text { between 2-10 are recognized }\end{array}$ & [78] \\
\hline NP10EO & FIIA & $2.4^{\mathrm{a}}$ & $5-250$ & Commercial monoclonal $\mathrm{Ab}$ & \multirow{4}{*}{ [79] } \\
\hline NP10EO & Direct ELISA & $8.9^{\mathrm{a}}$ & $10-500$ & Commercial monoclonal $\mathrm{Ab}$ & \\
\hline NP & FIIA & $52^{\mathrm{a}}$ & $100-5,000$ & Commercial monoclonal $\mathrm{Ab}$ & \\
\hline NP & Direct ELISA & $76^{\mathrm{a}}$ & $250-10,000$ & Commercial monoclonal $\mathrm{Ab}$ & \\
\hline NP & Direct ELISA & $769^{b}$ & $\mathrm{nr}$ & $\begin{array}{l}\text { Commercial ELISA plates with } \\
\mathrm{Ab} \text { immobilized } /\left({ }^{\beta} \text {-Gal tracer }\right)\end{array}$ & \multirow{7}{*}{ [80] } \\
\hline NP & CIA-GDH biosensor & $4,481^{\mathrm{b}}$ & $\mathrm{nr}$ & Commercial monoclonal $\mathrm{Ab}$ & \\
\hline OP & Direct ELISA & $346^{\mathrm{b}}$ & $\mathrm{nr}$ & $\begin{array}{l}\text { Commercial ELISA plates with } \\
\text { Ab immobilized } /\left({ }^{\beta} \text {-Gal tracer }\right)\end{array}$ & \\
\hline OP & CIA-GDH biosensor & $1,560^{\mathrm{b}}$ & $\mathrm{nr}$ & Commercial monoclonal $\mathrm{Ab}$ & \\
\hline NPE & Direct ELISA & $104^{\mathrm{b}}$ & $\mathrm{nr}$ & $\begin{array}{l}\text { Commercial ELISA plates with } \\
\text { Ab immobilized }(\stackrel{\beta}{ } \text {-Gal tracer })\end{array}$ & \\
\hline NPE & CIA-GDH biosensor & $378^{\mathrm{b}}$ & $\mathrm{nr}$ & Commercial monoclonal $\mathrm{Ab}$ & \\
\hline OPE & Direct ELISA & $42^{\mathrm{b}}$ & $\mathrm{nr}$ & Commercial ELISA plates with & \\
\hline
\end{tabular}




\begin{tabular}{|c|c|c|c|c|c|}
\hline Compound & $\begin{array}{l}\text { Immunochemical } \\
\text { technique }\end{array}$ & $\begin{array}{l}\mathrm{LOD}^{\mathrm{a}} / \mathrm{IC}_{50}{ }^{\mathrm{b}} \\
\left(\mu \mathrm{g} \mathrm{L}^{-1}\right)\end{array}$ & $\begin{array}{l}\text { Working range } \\
\left(\mu g \mathrm{~L}^{-1}\right)\end{array}$ & Comments & Ref \\
\hline & & & & Ab immobilized( ${ }^{\beta}$-Gal tracer $)$ & \\
\hline OPE & CIA-GDH biosensor & $605^{\mathrm{b}}$ & $\mathrm{nr}$ & Commercial monoclonal $\mathrm{Ab}$ & \\
\hline NPE & Automated BMP-IA & $6.6^{\mathrm{a}}$ & $6.6-66,000$ & Commercial monoclonal $\mathrm{Ab}$ & [81] \\
\hline NP & Indirect ELISA & $590^{\mathrm{b}}$ & $\mathrm{nr}$ & Polyclonal Ab & \\
\hline NP & PFIA & $\begin{array}{l}42,000^{\mathrm{b}} \\
7,900^{\mathrm{a}}\end{array}$ & $\mathrm{nr}$ & Polyclonal Ab & [79] \\
\hline $\begin{array}{l}{ }^{\mathrm{a}} L O D \text { limit } \\
{ }^{\mathrm{b}} \mathrm{C}_{50} \\
{ }^{\mathrm{c}} \mathrm{nr} \text { not rep } \\
C I A-G D H \text { b } \\
\text { ELISA enz) } \\
B M P-I A \text { ba } \\
\text { FIIA flow-in } \\
\text { PFIA polari }\end{array}$ & $\begin{array}{l}\text { of detection } \\
\text { orted } \\
\text { iosensor capillary in } \\
\text { yme linked immunos } \\
\text { cterial magnetic part } \\
\text { jection immunoassa } \\
\text { zation fluoroimmuno }\end{array}$ & $\begin{array}{l}\text { munoassay c } \\
\text { rbent assay } \\
\text { cles based im } \\
\text { assay }\end{array}$ & $\begin{array}{l}\text { upled to a gluco } \\
\text { munoassay }\end{array}$ & se dehydrogenase biosensor & \\
\hline
\end{tabular}

Several methodologies have been developed using these available monoclonal antibodies [79, 80, 81], all of them with the purpose of developing automated systems. The main results are shown in Table 1. Franek et al. have developed a generic FIIA for both NP and NPE10 [79]. The incubation step between the antibody, the analyte, and the labeled $\mathrm{Ag}\left(\mathrm{Ag}^{*}\right)$ is carried out off-line for a short time and then is injected in the flow system. The antibody is then retained in a protein $G$ packed column, whereas unbound $\mathrm{Ag}^{*}$ is eluted and measured. Despite of the competition step, the system can be considered fully automated and allows the analysis of 10 samples $\mathrm{h}^{-1}$. They have compared their system with the direct ELISA using the same kind of labels (in this case, the $\beta$-galactosidase, $\beta$-Gal) and the sensitivities accomplished are similar in both methods (see Table 1), and even slightly better for FIIA.

Another developed method consists of a capillary immunoassay coupled to an enzyme biosensor as the detector unit [80]. The system does not run fully automated, since the heterogeneous competition step and the elution of the unbound fraction are performed off-line. The capillary is then integrated in a flow-injection system with a GDH (glucose dehydrogenase) biosensor. The technique has been developed for NP, OP, NPE, and OPE, and the sensitivities have also been compared with the direct ELISA. The sensitivity is lower in the automated system; however, the specificity results showed the same trend (APEs are better recognized than APs) (see Table 1).

Matsunaga et al. have developed an automated heterogeneous immunoassay based on the immobilization of the monoclonal antibodies (from Takeda Industries) on bacterial magnetic particles [81] (i.e., magnetite particles synthesized by magnetic bacteria). The magnetic properties of these particles permit the easy separation of the immobilized reagent from the media in different sequential steps. Competitive assays have been carried out using APEs as the target analyte to obtain limits of detection which were quite good ( $\mathrm{LOD}=6.6 \mu \mathrm{g} \mathrm{L}{ }^{-1}$ ) (see Table 1) compared with the direct ELISA [76]. The system also studied the pattern of cross-reactivity with AP itself and APEs individually and the same profile was observed as in commercial indications of the direct ELISA (i.e., APEs are better recognized than APs). 
At present, only one other attempt has been reported regarding preparation of specific antibodies for APEs, in this case, polyclonal antibodies [79]. Several immunizing haptens were synthesized with a spacer arm in the alkyl position keeping the phenol group intact (hapten 1B in Scheme 1), that is, just the opposite strategy to that carried out by Goda et al.. The antibodies obtained were only tested against NP, and an indirect ELISA and a homogeneous PFIA have been developed; the LODs achieved by PFIA were almost 2 orders of magnitude higher (Table 1) than in the ELISA. Unfortunately there is a lack of information regarding antibody specificity for OP, APEs, or even APECs. This aspect would be interesting in order to discuss the differences encountered when using hapten $\mathbf{A}$ or $\mathbf{B}$ for raising antibodies.

Antibodies able to recognize all alkylphenolic compounds (including APEs and APs) could be enough depending on the requirements. However, specific antibodies only for $\mathrm{NP}$ would be still more useful, since this is the most estrogenic and persistent compound of the APEs and therefore more exhaustive and rapid controls are required to determine accurate levels in the environment. Finally, it can also be noted that for NP the sensitivities of the techniques developed are generally worse than for APEs. In most cases the dynamic range or the $\mathrm{IC}_{50}$ are in the order of the $\mathrm{mg} \mathrm{L}^{-1}$. The hydrophobicity of NP, which is quite high $(\log P=4.5)$, may explain the low sensitivity reached by these methods regarding APs. Since immunochemical techniques work by definition in aqueous media and the extent of organic solvent tolerated for the technique is usually very low (10-20\%), hydrophobic substances are sometimes difficult to measure. In these assay conditions NP probably presents problems of solubility or even of unspecific adsorption on the surfaces where the assay is carried out. These sensitivities are maybe enough for samples coming from wastewater, where the levels of NP are quite high, but for surface and groundwater more sensitive methods are still needed.

\section{Phthalate esters}

Phthalate esters have been extensively used as plasticizers in PVC production as well as a component in the manufacture of cosmetic products, adhesives, solvents, and inks. Several phthalates are used such as diethylhexylphthalate (DEHP), butylbenzylphthalate (BBP), dibutylphthalate (DBP), and dioctylphthalate (DOP). The most important one is DEHP, which represents over $90 \%$ of the total phthalates production, approximately 54,000 t year $^{-1}[82,83]$. The PVC resins have been used to manufacture a wide variety of products, from shower curtains, raincoats defoaming agents, animal glue, and enclosures for food containers to pacifiers, soft squeeze toys, and teething rings. The phthalates may then enter in the environment and food chain. Their fast biodegradation under aerobic conditions prevents their accumulation in water (the half-life is about several hours to 15 days) while in sediments it can be more persistent (with a half-life between 7 days and several months) [84]. It is well known that phthalates are testicular toxicants $[85,86]$. Concerning their disrupting effect, different in vitro studies have confirmed that phthalates such as BBP and DBP are weakly estrogenic [73, 87] (BBP is the phthalate with a highest activity and is 1-milion-fold less potent that the natural estrogen $17 \beta$-estradiol [88]). In vivo experiments have found that DBP and DEHP cause irregularities in male sexual differentiation $[89,90]$ and DBP have a weakly estrogenic activity although it seems that these possible effects occur at high concentrations [91]. Contradictory results have been found about the mechanism of action of these disrupters, since several studies seem to indicate that some phthalates act as antiestrogens [92]. Recently, Moore [93] has published a review with the current available data about the 
potential effects of phthalates. Phthalates have been found in industrial effluents, sewage sludges, and are also found in groundwater and drinking water [87]. The environmental levels found are approximately $10 \mu \mathrm{g} \mathrm{L}^{-1}$ in surface waters, $0.5-1 \mu \mathrm{g} \mathrm{L}^{-1}$ in rivers, and $0.005-0.7 \mu \mathrm{g} \mathrm{L}{ }^{-1}$ in seawater.

\section{Immunochemical techniques for phthalate esters}

The methods currently used to measure phthalate esters quantitatively are GC and HPLC. In addition, a few references report the use of immunochemical techniques. The first one [94] describes the development of a time-resolved fluoroimmunoassay (TRFIA) capable of measuring several phthalates: dimethylphthalate, diethylphthalate, DBP, $\mathrm{BBP}$, and DOP in water. The polyclonal antisera were obtained by immunizing with the molecule 2A (Scheme 2), which keeps the dimethylester group intact. The time of the assay is less than $3 \mathrm{~h}$ and the sensitivity achieved is good, with an LOD of about $97 \mathrm{ng} \mathrm{L}^{-1}$ for dimethylphthalate and a working range of between $97 \mathrm{ng} \mathrm{L}^{-1}$ and $388 \mu \mathrm{g} \mathrm{L}^{-1}$. The labels used in this type of immunoassay are europium chelates. These have interesting fluorescent properties such as a decay time that is much longer (near to hundreds of milliseconds) than other organic molecules (the values are in the nanoseconds range), which leads to good sensitivities. Although the most produced and used phthalate, DEHP, has not been tested, other important phthalates like BBP and DBP, and another octylphthalate (DOP) can be analyzed with this technique with good sensitivity and specificity. Moreover, little interference due to isomeric phthalic esters has been found, whereas phthalic acids are not recognized by the antisera used in the assay.

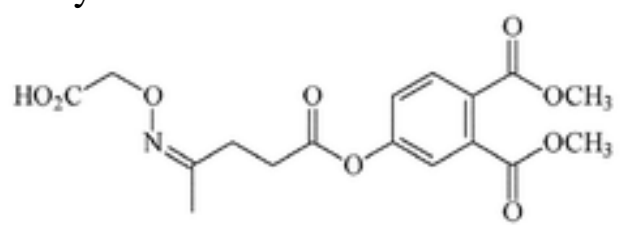

$2 A$

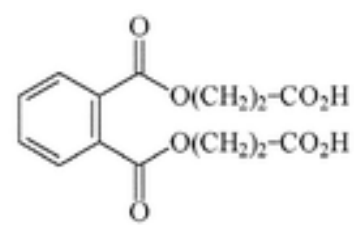

2B

Scheme 2A,B Chemical structures of the two immunizing haptens used to raise antibodies for phthalate esters. A Hapten used by lus et al. [94] to obtain polyclonal antibodies. B Hapten used by Goda et al. [76] to obtain monoclonal antibodies

On the other hand, Goda et al. [76] have developed a direct ELISA using specific monoclonal antibodies. By using DBP as standard, an assay with a limit of detection of $200 \mu \mathrm{g} \mathrm{L}^{-1}$ has been obtained. The dynamic range is $200-4,000 \mu \mathrm{g} \mathrm{L}^{-1}$. The sensitivity is not very good, and a possible reason could be the selection of the immunizing hapten. In this case the spacer arm has been introduced in both esters, blocking the two important epitopes in the molecule (structure 2B in Scheme 2). Regarding to the selectivity of the assay, the antibodies show good specificity for both BBP and DBP, but also in this case DEHP is not recognized. Thus, more attempts are needed to obtain immunochemical methodologies capable of detecting this main phthalate.

\section{Bisphenol A}

Bisphenol A [2,2-bis (4-hydroxydiphenyl)propane, BPA)] is a major component in the production of polycarbonate plastics and epoxy resins. These materials are used for 
several applications such as in food and drink plastic packages, food can linings, and dental composite fillings. Other minor uses involve its application as antioxidant, preservative, and in the production of flame-retardant components. However, the production of resins remains the most common application area. Incomplete polymerization or partial hydrolysis of the polymers leads to release of bisphenol A from the flasks into food; this is the origin of human exposure to BPA [95, 96]. Bisphenol A is not only a food contaminant but also an environmental pollutant, since its presence has been detected in sewage effluents, with values often below $1 \mu \mathrm{g} \mathrm{L}^{-1}[97$, 98], and in surface water, with concentrations even lower (in the range $0.001-1 \mu \mathrm{g} \mathrm{L}^{-1}$ ) [97, 99]. However, the biodegradation of bisphenol A is quite rapid in surface water (with a half-life of $0.5-6$ days) $[100,101]$ and also in rivers sediments (although it has been detected [99]), and is extensively removed in the wastewater treatment plants (WWTPs). Apart of acute toxicity, the disrupting effects of bisphenol A have been studied for several years [4]: BPA has weak estrogenic activity at concentrations of about $2-5 \mu \mathrm{g} \mathrm{L}^{-1}$ [96]. Also a possible antiandrogenic activity seems to be caused by BPA [92]. Several studies have shown that BPA induces alteration in reproductive organs in female rats [102] as well as in male mice, rats [103], and fish [104]. Because of its human exposure risk and its evident disrupting effect, several methods have been developed to detect BPA, such as GC-MS [105], HPLC-UV [106], or HPLC-MS [74, 75], not only in environmental samples but also in beverages [107], serum [108], and semen [109].

\section{Immunochemical techniques for bisphenol A}

Many more attempts have been carried out to develop sensitive immunochemical methods for BPA than for the other ECDs considered in this review as summarized in Table 2. Goda et al. have also produced monoclonal antibodies and developed a direct ELISA with a limit of detection of $5 \mu \mathrm{g} \mathrm{L}^{-1}$ [76]. In the immunizing hapten the spacer arm has been introduced in the position occupied by one hydroxyl group in BPA (see hapten $\mathbf{3 A}$ in Scheme 3). The working range of the assay is $5-500 \mu \mathrm{g} \mathrm{L}^{-1}$. Only two different bisphenolic compounds, those who have either one or two hydrogen atoms instead of the methyl groups, are well recognized with cross-reactivities of $144 \%$ and $73 \%$, respectively, whereas metabolites of BPA and other related compounds do not interact with the antibodies. These high cross-reactivities are not a problem, since both compounds are produced in much lower amounts than BPA. An optimized ELISA kit with monoclonal antibodies has also been commercialized by Takeda Chemical Industries. In this case, a more sensitive assay has been achieved with a dynamic range of $0.05-10 \mu \mathrm{g} \mathrm{L}^{-1}$. Related bisphenolic compounds, other EDCs, surfactants, and fumic acids have been tested and no cross-reactivity has been observed.

Table 2 Immunochemical techniques developed for the detection of bisphenol A

\begin{tabular}{|c|c|c|c|c|c|}
\hline Compound & $\begin{array}{l}\text { Immunochemical } \\
\text { technique }\end{array}$ & $\begin{array}{l}\mathrm{LOD}^{\mathrm{a}} / \mathrm{IC}_{50} \\
\left(\mu \mathrm{g} \mathrm{L}^{-1}\right)\end{array}$ & $\begin{array}{l}\text { Working } \\
\text { range }\left(\mu \mathrm{g} \mathrm{L}^{-1}\right)\end{array}$ & Comments & Ref \\
\hline \multirow{6}{*}{$\begin{array}{l}\text { Bisphenol } \\
\text { A }\end{array}$} & Direct ELISA & $5^{\mathrm{a}}$ & $5-500$ & Monoclonal Ab & {$[76]$} \\
\hline & $\begin{array}{ll}\text { Commercial Direct } \\
\text { ELISA Kit }\end{array}$ & $0.05^{\mathrm{a}}$ & $0.05-10$ & Monoclonal Ab & {$[78]$} \\
\hline & Automated BMP-IA & $0.0023^{\mathrm{a}}$ & $0.0023-2,300$ & Commercial monoclonal Ab & {$[81]$} \\
\hline & Indirect ELISA & $570^{\mathrm{b}}$ & $\mathrm{nr}^{\mathrm{c}}$ & Chicken polyclonal $\mathrm{Ab}$ & [110] \\
\hline & Indirect ELISA & $0.1^{\mathrm{a}}$ & $1-10,000$ & Polyclonal Ab & {$[111]$} \\
\hline & IAC & - & - & Extraction of BPA from & [112] \\
\hline
\end{tabular}




\begin{tabular}{|l|l|l|l|l|l||}
\hline Compound & $\begin{array}{l}\text { Immunochemical } \\
\text { technique }\end{array}$ & $\begin{array}{l}\mathbf{L O D}^{\mathbf{a}} / \mathbf{I C}_{\mathbf{5 0}} \\
\left(\boldsymbol{\mu g} \mathbf{L}^{-\mathbf{1}}\right)\end{array}$ & $\begin{array}{l}\text { b } \\
\text { terking } \\
\text { range }\left(\boldsymbol{\mu g} \mathbf{~ L}^{-\mathbf{1}}\right)\end{array}$ & Comments & Ref \\
\hline & & & $\begin{array}{l}\text { serum samples using } \\
\text { polyclonal Ab }\end{array}$ & \\
\hline Direct ELISA & $0.3^{\mathrm{a}}$ & $0.3-100$ & Polyclonal Ab & {$[113]$} \\
\hline
\end{tabular}

a $L O D$ limit of detection

${ }^{\mathrm{b}} \mathrm{IC}_{50}$

${ }^{\mathrm{c}} \mathrm{nr}$ not reported

ELISA enzyme linked immunosorbent assay

$B M P-I A$ bacterial magnetic particles based immunoassay

$I A C$ immunoaffinity chromatography<smiles>CC(C)(c1ccc(O)cc1)c1ccc(OC(=O)CCCC(=O)O)cc1</smiles><smiles>CC(CCC(=O)O)(c1ccc(O)cc1)c1ccc(O)cc1</smiles>

$3 \mathrm{~A}$<smiles>CC(C)(C)C(=O)Oc1ccc(C(C)(C)c2ccc(O)cc2)cc1</smiles>

$\mathrm{n}=1,3,4$

$3 \mathrm{C}$

Scheme 3A-C Chemical structures of several immunizing haptens used to obtain antibodies against bisphenol A. A Hapten used to produce both monoclonal [76] and polyclonal [110] antibodies by Goda et al. and DeMeulenaer et al., respectively. B Hapten used to produce polyclonal antibodies by Zhao et al. [111]. C Different haptens used to obtain polyclonal antibodies [113] by Ohkuma et al.

As in the case of APEs, Matsunaga et al. [81] have developed an automated immunoassay based on the immobilization of these monoclonal antibodies on bacterial magnetic particles. The sensitivity of this assay is very good with a detection range of $2.3 \mathrm{ng} \mathrm{L}^{-1}$ to $2.3 \mathrm{mg} \mathrm{L}^{-1}$, that is, even better than the direct ELISA and conventional chromatographic methods.

Other attempts have been carried out to obtain specific antibodies. De Meulenaer et al. [110] have developed an indirect competitive ELISA with polyclonal antibodies obtained from chicken egg yolk. The immunizing hapten conjugated to BSA is the same one used by Goda et al. (hapten $\mathbf{3 A}$ in Scheme 3). Several parameters in the assay have been optimized to finally obtain an ELISA with an $\mathrm{IC}_{50}$ value of about $570 \mu \mathrm{g} \mathrm{L}^{-1}$. Also, several other bisphenol and phenolic compounds and phthalates have been tested observing that only two bisphenolic compounds were recognized with a maximum value of $43 \%$ cross-reactivity for the bisphenol with only one hydroxyl group. Better results have been obtained by Zhao et al. [111] who produced polyclonal antibodies against the hapten 3B shown in Scheme 3. In this case, both hydroxyls groups in the molecule have been preserved and the analyte has been derivatized by one of the methyl groups. An indirect ELISA has been obtained with a linear range of $1-10,000 \mu \mathrm{g} \mathrm{L}^{-1}$ and a limit of detection of $0.1 \mu \mathrm{g} \mathrm{L}^{-1}$ on real water samples. Serum samples have been also analyzed, and a dilution factor of 1:10 was needed. The limit of detection achieved 
in this case was $2 \mu \mathrm{g} \mathrm{L}^{-1}$. Phenolphthalein, as a structure that has the bisphenol pattern, has been evaluated and shows little cross-reactivity. The antibodies did not recognize other simple phenolic compounds tested. Subsequently, these antibodies were also used to develop immunoaffinity columns for the selective extraction of bisphenol A from serum samples [112] to obtain an analyte recovery value of about $90 \%$.

Ohkuma et al. have also developed a direct ELISA [113] with a limit of detection of $0.3 \mu \mathrm{g} \mathrm{L}{ }^{-1}$ for human serum samples, and a working range of $0.3-100 \mu \mathrm{g} \mathrm{L}^{-1}$. Several haptens based on the formation of carboxyalkylethers, such as methyl, propyl, and butylethers, were prepared in order to raise antibodies in rabbits. The analyte recoveries found in spiked serum samples were 82-97\%, without important nonspecific matrix effects. The specificity of the assay was good since only bisphenol B (with an ethyl group instead of one of the two methyl substituents in bisphenol A) interfered in the assay with a cross-reactivity value of $13 \%$.

Finally, immunochemical methods have been developed using monoclonal antibodies selected for their high resistance to organic solvent (up to 50\% of methanol). Assays could be run in these conditions at levels of around $1 \mu \mathrm{g} \mathrm{L}^{-1}$. Other polyclonal antibodies were used to selectively detect bisphenol $\mathrm{A}$ in urine samples at concentration levels of $0.5-5 \mu \mathrm{g} \mathrm{L}^{-1}[114]$.

\section{Polychlorinated biphenyls (PCBs)}

Polychlorinated biphenyls (PCBs) are one of the most hazardous, persistent, and toxic man-made compounds. They are a class formed by 209 discrete congeners in which 110 chlorine atoms can be bound to the biphenyl nucleus. They were produced until the 1970-1980s, when their toxic effects began to be discovered. Since the 1930s, these compounds were commercialized as mixtures of several congeners (with commercial names like Aroclor, Clophen, etc.) and were widely used in many industrial applications such as lubricants, dielectric fluids in electrical transformers and capacitors, hydraulic fluids, and as additives in plastics, adhesives, sealants, and copying paper. They are inert, heat resistant, and nonflammable and these properties make the compounds of this family very persistent in the environment. Their high hydrophobicity leads to adsorption mainly in sediments, soils, and sludge. They are also bioaccumulated in adipose tissue and in milk [12]. The human exposure comes mainly from indirect exposure through food (fish) and mother "s milk.

PCBs can be coplanar or noncoplanar and they differ in their toxicology. Only 12 of the 209 congeners seem to have a toxic level similar to dioxins, and all of them are called coplanar PCBs. They have no, or just one, chlorine atom in the ortho position, two chlorines in para positions, and at least one in a meta position. Three of the most toxic congeners are less abundant and are 3,4,3',4'-tetrachlorobiphenyl (PCB 77), 3,4,3',4',5'-pentachlorobiphenyl (PCB 129), and 3,4,5,3',4',5'-hexachlorobiphenyl (PCB 169). The toxicology of these compounds include carcinogenic, tetarogenic, tumorigenic reproductive and immunotoxic effects, and they also have disrupting effects causing reproductive alterations, endometriosis, thyroid dysfunction, increase in uterus weight, or ovarian growth impairment $[12,115,116,117]$. PCBs can also undergo anaerobic reductive dehalogenation in river sediments [118]. It seems that their hydroxylated metabolites can also induce an estrogenic effect [73, 119]. 
This family of products has been extensively studied in recent years and has been analyzed with conventional techniques (e.g., GC-MS) that usually require clean-up and pretreatment process in order to separate the most toxic congeners, which often are the analyte of interest.

\section{Immunochemical techniques for PCBs}

Although PCBs are highly lipophilic and the immunochemical techniques require an aqueous media to be carried out, several attempts have been made to obtain specific antibodies against PCBs and to develop immunoassays for their detection and quantification. The first ones date from the 1980s [120,121] and some later studies are briefly reviewed by Diaz-Ferrero et al. [122]. Often these assays have been developed not for the detection of specific congeners but for the detection of commercial products like Aroclor, and the immunizing hapten is the derivatized Aroclor or a PCB congener. Several radioimmunoassays (RIAs) have been developed using polyclonal antibodies and have been used to detect Delor 106 in milk [123] and Aroclor 1248 in milk and blood [29, 124]. Other immunoassays have also been reported to detect Aroclors or the most abundant and also less toxic noncoplanar PCBs in soil, water, and sediments (see Table 1 in ref. [122]) [125, 126, 127, 128].

More recently, other immunochemical techniques have been reported for the detection of PCBs. Johnson et al. [129] obtained polyclonal antibodies for Aroclor by using hapten 4A (Scheme 4) as the immunizing hapten. An indirect competitive microtiter plate ELISA was developed. Several Aroclors were tested and the most recognized ones were Aroclor 1242, 1248, 1254, 1260, and 1262 with $\mathrm{IC}_{50}$ values of $10-31 \mu \mathrm{g} \mathrm{L}^{-1}$ and limits of detection of around $1.3 \mu \mathrm{g} \mathrm{L}^{-1}$ in water and $9 \mathrm{ng} \mathrm{g}^{-1}$ in soil. The specificity of the assay was also tested using a great variety of compounds as potential cross-reactants (chlorophenols, chloroanisols, chlorobenzenes, etc.) showing that none of them was recognized more than $3 \%$.

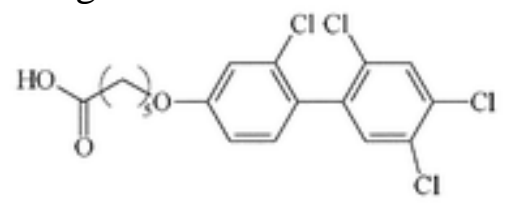

$4 A$

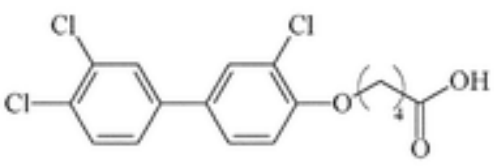

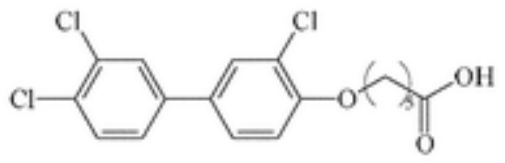

$4 B$

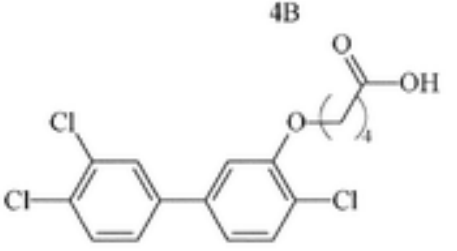

$4 \mathrm{C}$

Scheme 4A-C Chemical structures of two immunizing haptens used to raise antibodies towards PCBs. A Hapten used by Johnson et al. [129] to obtain polyclonal antibodies. B Hapten used by Chiu et al. [131] to obtain monoclonal antibodies against coplanar PCBs. C Mixtures of haptens used by Concejero et al. [132] to raise polyclonal antibodies

Lawruk et al. [130] have developed a magnetic particle-based immunoassay using Aroclor 1254 as the immunizing hapten to obtain polyclonal antibodies. The limit of 
detection of the assay is of $0.2 \mu \mathrm{g} \mathrm{L}^{-1}$ in water and $500 \mu \mathrm{g} \mathrm{Kg}^{-1}$ in soil. Several Aroclors cross-reacted, and also PCB $129\left(3,4,3^{\prime}, 4^{\prime}, 5^{\prime}\right.$-pentachlorobiphenyl) was well recognized. The assay can provide 50 analytical results in less than $1 \mathrm{~h}$, and its feasibility allows its adaptation to on-line monitoring of PCBs in water and soils.

To the best of our knowledge, most of the immunoassays reported have used polyclonal antibodies for the detection of Aroclors. Only one attempt has been reported based on the production of monoclonal antibodies used to detect the specific coplanar PCB congeners which are the most toxic and the less abundant: PCB 77,126, and 169 [131]. The immunizing hapten $\mathbf{4 B}$ is shown in Scheme 4 and was chosen because of the substitution pattern $\left(3,4,3^{\prime}, 4^{\prime}\right)$ that is common in the three congeners considered. Also, the spacer arm in the para position allowed the coplanarity of the biphenyls to be retained. Both direct and indirect competitive assays were developed and the best results were obtained for PCB 77 and 126 (around $1 \mu \mathrm{g} \mathrm{L}^{-1}$ ). The specificity of the assay is high since several noncoplanar PCBs were tested and were poorly recognized. Also PCDD, PCDF, and PCB metabolites were evaluated and were not recognized.

By using the same kind of immunizing hapten (with one carbon less in the spacer arm than described by Chiu et al. [131]), Concejero et al. [132] recently produced polyclonal antibodies to prepare immunoaffinity columns. An immunoaffinity chromatography procedure has been developed to selectively clean up and isolate liquid PCB samples prior to GC-MS analysis. In particular, coplanar PCBs and the most toxic PCDSs and PCDFs were extracted with high recoveries.

Several PCB antibodies and PCB immunoassay kits are commercially available with different formats and applications. Some of them are performed in coated test tubes such as the EnviroGard PCB Test Kit or EnSys (SDI Europe Ltd., UK), in magnetic particles such as the PCB RaPID Assay (SDI Europe Ltd., UK). There are also latex particles/membrane immunoassay kits (D Tech, SDI Europe Ltd., UK). All of them are rapid and simple methods and allow the analysis of water samples and soil and wipe matrices but work at semiquantitative or qualitative levels. By using commercial monoclonal antibodies an indirect ELISA has been developed to detect PCBs in insulating oils [133]. The optimized assay presents a working range for Aroclors 1254 and 126 of $30-1,000 \mu \mathrm{g} \mathrm{L}^{-1}$, an $\mathrm{IC}_{50}$ value near to $215 \mu \mathrm{g} \mathrm{L}^{-1}$, and an LOD of about $25 \mu \mathrm{g} \mathrm{L}^{-1}$ and $40 \mu \mathrm{g} \mathrm{L}^{-1}$ for Aroclor 1254 and 1260, respectively.

Finally, a fiber optic immunosensor has been developed for PCBs detection [63], with a sensitivity limit for Aroclor 1242 of $10 \mu \mathrm{g} \mathrm{L}^{-1}$. Other Aroclors are also recognized, whereas polychlorophenols, polychlorobenzenes, and other chlorinated compounds have a low degree of cross-reactivity.

\section{Polychlorinated dibenzofurans (PCDFs) and polychlorinated dibenzo-p-dioxins (PCDDs)}

Both PCDDs and PCDFs (commonly referred to as dioxins) are a group of widespread environmental pollutants of great concern during recent years due to their harmful effects for the health. As well as for PCBs, many congeners exist depending on the number and position of the chlorine atoms (75 for dioxins and 135 for furans). These pollutants have a high chemical stability and extremely poor water solubility (about 
$20 \mathrm{ng} \mathrm{L}^{-1}$ for TCDD, 2,3,7,8-tetrachlorodibenzo-p-dioxin). But, unlike PCBs, these recalcitrant and persistent compounds are not produced intentionally, but are generated as undesired by-products in several processes, mainly combustion processes such as waste incineration. Other sources of dioxins are from bleaching of pulp with chlorine, metal production, and synthesis of halogenated compounds such as chlorophenols. Due to their highly lipophilic nature, these compounds tend to be adsorbed and accumulated in sediments and soils. On the other hand, wildlife and human exposure comes from the emission at production and at waste stage (incineration) and through food (they have been found in fish, meat, and other dairy products) and mother "s milk.

The most toxic dioxin seems to be TCDD and is proven to cause cancer in humans [134]. The effects of the other congeners depend on the position and number of chlorine atoms and it seems that the 2,3,7,8 chlorination pattern is required for dioxin-like toxicity. TCDD and other PCDDs and PCDFs have been shown to induce disrupting effects [135], such as the reduction of fertility due to their action on the hormones of the reproductive system, thyroid effects, decrease of sperm number in males and uterus weight in females.

The ubiquity of these substances in the environment and their clearly demonstrated toxicity have led to continuous analysis by different methodologies. Of these, highresolution gas chromatography coupled to mass spectrometry (HRGC-HRMS) was the most used until several years ago. During recent decades much effort has been made in biotechnology in order to develop in vitro bioassays and ligand binding assays that may allow the analysis of large numbers of samples as well as an improvement in the accuracy and reliability of the results. An extensive review with the recent bioanalytical techniques developed for dioxin detection, including immunoassays, has been recently reported [136].

\section{Immunochemical techniques for PCDFs and PCDDs}

As well as in the case of PCBs and other compounds, the high hydrophobicity of these substances may imply a drawback in the application of immunochemical techniques for their detection and several considerations must be taken into account such as the hapten design, the organic solvent compatibility, and the handling of the standard solutions. In the literature, complete reviews can be found focusing on the immunochemical analysis of dioxins, paying special attention to antibody production, sample preparation, cleanup methods, sensitivity of immunoassays developed, etc. as well as in immunoassays and other bioassays for polychlorinated compounds [122, 137].

The first immunochemical technique reported for detection of dioxins was in 1979 and was a RIA [138] developed with polyclonal antibodies. The method developed was very time-consuming and both dioxins and furans were well recognized. Further optimization was carried out to improve the assay sensitivity and precision [139] using solubilization agents. Later Kennel et al. [140] obtained monoclonal antibodies that successfully recognized carrier-protein-bound dioxins but not the free form in solution. The assay was performed with a solid-phase RIA configuration. Other immunoassays using monoclonal antibodies were developed in the 1980s by Stanker et al. [141, 142] that were applied to detect dioxins in soils [143] and for rapid screening of dioxins and furans $[144,145,146,147]$. These ELISAs had a sensitivity similar to the RIA (an IC 50 value about $200 \mathrm{pg}$ TCDD well ${ }^{-1}$ ). Langley et al. [148] also reported an ELISA with 
polyclonal antibodies with a sensitivity of $1 \mathrm{ng}$ well $^{-1}$ using 2,3,7,8-TCDD as standard. More recent works have focused on the design and synthesis of new haptens to improve the already existing IAs or to produce more specific antibodies [149]. Sugawara et al. [150] have also obtained specific polyclonal antibodies against PCDDs, and have developed an indirect competitive ELISA with high sensitivity (the $\mathrm{IC}_{50}$ value is of $240 \mathrm{ng} \mathrm{L}^{-1}$ and a working range of 40-4,800 $\mathrm{ng} \mathrm{L}^{-1}$ ). Several PCDDs and even PCDFs are well recognized, mainly those with the 2,3,7,8 substitution pattern. Subsequently Shan et al. [151] improved this immunoassay by using a different coating antigen and obtained a more sensitive ELISA with a LOD of $4 \mathrm{ng} \mathrm{L}^{-1}$ and an $\mathrm{IC}_{50}$ value of $36 \mathrm{ng} \mathrm{L}^{-1}$.

During recent years several works have been reported on the development of immunoaffinity columns for selective extraction of dioxins and furans. Both monoclonal [152] and chicken polyclonal antibodies [153] have been used to prepare the immunosorbents. The immunoaffinity column procedures were optimized to subsequently isolate and analyze these compounds from serum samples and the recoveries for both columns have also been compared [154]. Finally, several commercial dioxin immunoassay kits are available (e.g., Envirogard, EnSys, and Dioxin RISC from SDI Europe Ltd., UK; DD3 from Millipore Inc., USA and High Performance dioxin/furan EIA from CAPE Technologies, USA).

\section{Conclusions}

It has been widely demonstrated that immunochemical techniques offer a good alternative to conventional methodologies in many areas due to the high sensitivity and selectivity achieved for the antibodies towards the target analytes. In clinical and environmental analysis, their use has been broadly spread because of their sensitivity, specificity, and high sample processing capabilities. For the case of man-made pollutants with endocrine disrupting activity and high risk of human and wildlife exposure presented in this review, a variety of immunochemical methods have been developed covering sample treatment methods (i.e., immunosorbents) and analytical methods such as several immunoassays formats (RIA, ELISA, PFIA, FIIA) and immunosensors. For human and environmental safety reasons, the use of RIA methods has been dismissed in favor of the assays using enzymes or fluorescent/chemiluminescent labels. Unfortunately, some of these methods are not yet being used as regular screening and analytical methods in food-safety and environmental control laboratories. A reason for this may be the lack of knowledge on the performance of this type of techniques by certain analytical sectors and also by the lack of validated protocols for a wide range of sample matrices. Immunoassay methods may suffer from undesirable matrix effects that may lead to wrong positive or negative results. It is an incorrect assumption that the selectivity of the immunochemical reaction is sufficiently high enough to overcome nonspecific interactions of the antibodies with the matrix components. Rigorous evaluation of the performance of these methods on each sample matrix of interest and the consequent establishment of appropriate sample treatment methods are required to ensure reliability and to convince control laboratories of the efficiency of these techniques. A tight collaboration and interchange of expertise between analytical chemists and immunochemists are needed to accomplish this goal and to take advantage of these methods to assess risk and protect public health from the adverse effects of these types of pollutants. 
Acknowledgments This work was supported by INIA (VINO0-053-C3-2), the EC Quality of Life Program (Contract QLRT-2000-01670), and by CICYT (BIO20000351-P4-05, AGL2001-5005-E and AGL2002-04635-C04-03).

\section{References}

1. Ferguson SA, Scallet AC, Flynn KM, Meredith JM, Schwetz BA (2000) Neurotoxicol 21:947-956

2. Guillesby B, Zacharewski TR (1998) Environ Toxicol Chem 17:3-14

3. Safe SH (1998) Ann Rev Pharmacol Toxicol 38:121-158

4. Sonnenschein C, Soto AM (1998) J Steroid Biochem Mol Biol 65:143-150

5. Thonneau P, Bujan L, Multigner L, Mieusset R (1998) Human Reprod 13:2122-2125

6. Damgaard NI, Main KM, Toppari J, Skakkebaek NE (2002) Best Pract Res Clin Endocrinol Metabol 16:289-309

7. Markey CM, Rubin BS, Soto AM, Sonnenschein C (2002) J Steroid Biochem Mol Biol 83:235-244

8. Tapiero H, Nguyen Ba G, Tew KD (2002) Biomed Pharmacother 56:36-44

9. Amaral Mendes JJ (2002) Food Chem Toxicol 40:781-788

10. Maczka C, Pang S, Policansky D, Wedge R (2000) Environ Sci Technol 34:136A-141A

11. Witorsch RJ (2002) Regul Toxicol Pharmacol 36:118-130

12. Groshart C, Okkerman PC (2000) Endocrine disrupting substances (man-made chemicals). Towards the establishment of a priority list of substances for further evaluation of their role in endocrine disruption. M0355008 BKH Consulting Engineers, NL

13. Colborn T, Vom Saal FS, Soto AM (1993) Environ Health Perspect 101:378-384

14. Silva E, Rajapakse N, Kortenkamp A (2002) Environ Sci Technol 36:1751-1756

15. Lopez de Alda MJ, Barcelo D (2001) Fresenius J Anal Chem 371:437-447

16. Yin G-G, Kookana Rai S, Ru YJ (2002) Environ Int 28: 545-551.

17. Coille I, Reder S, Bucher S, Gauglitz G (2002) Biom Eng 18: 273-280

18. Huang CH, Sedlak DL (2001) Environ Toxicol Chem 20: 133-139

19. Armstrong S, Miao ZF, Rowell FJ, Ali Z (2001) Anal Chim Acta 444:79-86

20. Valentini F, Compagnone D, Gentili A, Palleschi G (2002) Analyst 127:1333-1337

21. Muir C, Spironello-Vella E, Pisani N, DeCatanzaro D (2001) Horm Metab Res 33:653-658

22. Agasan AL, Briggs MH, Hewish DR, Stewart B (1986) Steroids 47:295-306.

23. Aherne GW, English J, Marks V (1985) Ecotoxicol Environ Safety 9:79-83

24. Gonzalez Martinez MA, Puchades R, Maquieira A (1999)Trends Anal Chem 18:204-218

25. Gabaldon JA, Maquieira A, Puchades R (1999) Crit Rev Food Sci Nutr 39:519-538

26. Hogendoorn E, van Zoonen P (2000) J Chromatogr A 892: 435-453

27. Dankwardt A, Hock B (1997) Food Technol Biotechnol 35: 165-174

28. Marco MP, Gee S, Hammock BD (1995) Trends Anal Chem 14:415-425

29. Niessner R (1993) Anal Methods Instrum 1:134-144

30. Van Emon JM, Lopez-Avila V (1992) Anal Chem 64:79A- 88A

31. Meulenberg EP, Mulder WH, Stoks PG (1995) Environ Sci Technol 29:553-561

32. Hage DS (1999) Anal Chem 71:294R-304R

33. Oubina A, Ballesteros B, Bou Carrasco P, Galve R, Gascon J, Iglesias F, Sanvicens N, Marco MP (2000) Immunoassays for environmental analysis. In: Barcelo D (ed) Sample handling and trace analysis of pollutants: techniques, applications and quality assurance. ElsevierAmsterdam, pp 287-339

34. Hennion MC, Barcelo D (1998) Anal Chim Acta 362:3-34

35. Wortberg M, Cammann K (1993) Fresenius J Anal Chem 346: 757-760

36. Schlaeppi J-MA, Kessler A, Fory W (1994) J Agric Food Chem 42:1914-1919

37. Matveeva EG, Aguilarcaballos MP, Eremin SA, Gomezhens A, Perezbendito D (1997) Analyst 122:863-866

38. Onnerfjord P, Eremin S, Emneus J, Markovarga G (1998) J Immunol Meth 213:31-39

39. Matveeva EG, Samsonova ZV, Eremin SA (1996) Bioorg Khim 22:931-937 
40. Garcia Sanchez F, Navas A, Alonso F, Lovillo J (1993) J Agric Food Chem 41:2215-2219

41. Kramer P, Schmid R (1991) Biosens Bioelectron 6:239-243

42. Puchades R, Maquieira A, Atienza A, Montoya A (1992) Crit Rev Anal Chem 23:301

43. Puchades R, Maquieira A (1996) Crit Rev Anal Chem 26:195

44. Gascon J, Oubina A, Ballesteros B, Barcelo D, Camps F, Marco MP, Gonzalez-Martinez MA, Morais S, Puchades R, Maquieira A (1997) Anal Chim Acta 347:149-162

45. Wittmann C, Schmid RD (1994) J Agric Food Chem 42: 1041-1047

46. Onnerfjord P, Eremin SA, Emneus J, Markovarga G (1998) J Chromatogr A 800:219-230

47. Charles PT, Jacobs MS, Bart JC, Kusterbeck AW (1995) Bioconj Chem 6:691-694

48. Ballesteros B, Marco MP (1998) Food Technol Biotechnol 36:145-155

49. Delaunay N, Pichon V, Hennion M-C (2000) J Chromatogr B Biomed Sci Appl 745:15-37

50. Rollag JG, Beckwestermeyer M, Hage DS (1996) Anal Chem 68:3631-3637

51. Lawrence JF, Menard C, Hennion MC, Pichon V, Le Goffic F, Durand N (1996) J Chromatogr A 752:147-154

52. Thomas DH, Lopezavila V, Betowski LD, Van Emon JM (1996) J Chromatogr A 724:207217

53. Pichon V, Chen L, Hennion MC, Daniel R, Martel A, Le Goffic F, Abian J, Barcelo D (1995) Anal Chem 67: 2451-2460

54. Rule GS, Mordehal AV, Henion J (1994) Anal Chem 66: 230-235

55. Marco MP, Gee SJ, Hammock BD (1995) Trends Anal Chem 14:341-350

56. Van Emon JM, Gerlach CL, Bowman K (1998) J Chromatogr B Biomed Sci Appl 715:211228

57. Marco MP, Barcelo D (eds) (2000) Fundamentals and applications of biosensors for environmental analysis. In: Sample handling and trace analysis of pollutants: techniques, applications and quality assurance. Elsevier, Amsterdam, pp 1075-1105

58. Rodriguez S, Marco MP, Lopez de Alda MJ, Barcelo B (2003) (included in this current volume-Special Issue in Endocrine Disruptors)

59. Luppa PB, Sokoll LJ, Chan DW (2001) Clin Chim Acta 314:

$1-26$

60. Khomutov SM, Zherdev AV, Dzantiev BB, Reshetilov AN (1994) Anal Lett 27:2983-2995

61. Brecht A, Piehler J, Lang G, Gauglitz G (1995) Anal Chim Acta 311:289-299

62. Gonzalez-Martinez MA, Morais S, Puchades R, Maquieira A, Abad A, Montoya A (1997)

Anal Chem 69:2812-2818

63. Zhao CQ, Anis NA, Rogers KR, Kline RH Jr, Wright J, Eldefrawi AT, Eldefrawi ME (1995)

J Agric Food Chem 43:2308-2315

64. Sadik OA, Van Emon JM (1996) Biosens Bioelectron 11:1-11

65. Renner R (1997) Environ Sci Technol 31:316A-320A

66. Scott MJ, Jones MN (2000) Biochim Biophys Acta (BBA) Biomembranes 1508:235-251

67. Ahel M, Giger W, Koch M (1994) Water Res 28:1131-1142

68. Ahel M, Molnar E, Ibric S, Giger W (2000) Water Sci Technol 42:15-22

69. La Guardia MJ, Hale RC, Harvey E, Mainor TM (2001) Environ Sci Technol 35:4798-4804

70. Ying GG, Williams B, Kookana R (2002) Environ Int 28:215-226

71. Jobling S, Sumpter JP (1993) Aquatic Toxicol 27:361-372

72. White R, Jobling S, Hoare SA, Sumpter JP, Parker MG (1994) Endocrinology135:175-182

73. Soto AM, Sonnenschein C, Chung KL, Fernandez MF, Olea N, Serrano FO (1995) Environ Health Perspect 103:113-122

74. Petrovic M, Eljarrat E, Lopez de Alda MJ, Barcelo D (2002) J Chromatogr A 974:23-51

75. Jeannot R, Sabik H, Sauvard E, Dagnac T, Dohrendorf K (2002) J Chromatogr A 974:143159

76. Goda Y, Kobayashi A, Fukuda K, Fujimoto S, Ike M, Fujita M (2000) Water Sci Technol 42:81-88

77. Fujimoto S, Goda Y (2000) Nippon Rinsho Japan J Clin Med 58:2491-2494

78. Takeda Chemical Industries L-EC. http://www.takeda.co.jp/index-e.html. Cited 27 May 2003 
79. Franek M, Zeravik J, Eremin SA, Yakovleva J, Badea M, Danet A, Nistor C, Ocio N, Emneus J (2001) Fresenius J Anal Chem 371:456-466

80. Rose A, Nistor C, Emneus J, Pfeiffer D, Wollenberger U (2002) Biosens Bioelectron 17:1033-1043

81. Matsunaga T, Ueki F, Obata K, Tajima H, Tanaka T, Takeyama H, Goda Y, Fujimoto S (2003) Anal Chim Acta 475:75-83

82. Report on carcinogens, 10th edn (2002) US Department of Health and Human Services, Public Health Service, national toxicology program. http://ehp.niehs.nih.gov/roc/. Cited 27 May 2003

83. Angelidaki I, Mogensen AS, Ahring BK (2000) Biodegradation 11:377-383

84. Staples CA, Peterson DR, Parkerton TF, Adams WJ (1997) Chemosphere 35:667-749

85. Wine RN, Li LH, Barnes LH, Gulati DK, Chaplin RE (1997) Environ Health Prespect 105:102-107

86. Li LH, Jester WF, Orth JM (1998) Toxicol Appl Pharmacol 153:258-265

87. Jobling S, Reynolds T, R W, Parker M, Sumpter J (1995) Environ Health Prespect 103:582587

88. Harris CA, Hentu P, Parker MG, Sumpter JP (1997) Environ Health Prespect 105:802-811

89. Gray LE, Wolf C, Lambright C, Mann P, Price M, Cooper RL, Ostby J (1999) Toxicol Industr Health 15:94-118

90. Mylchreest E, Cattley RC, Foster PMD (1998) Toxicol Sci 43:47-60

91. Thorpe KL, Hutchinson TH, Hetheridge MJ, Sumpter JP, Tyler CR (2000) Environ Toxicol Chem 19:2818-2820

92. Sohoni P, Sumpter JP (1998) J Endocrinol 158:327-339

93. Moore NP (2000) Reproductive Toxicol 14:183-192

94. Ius A, Bacigalupo MA, Meroni G, Pistillo A, Roda A (1993) Fresenius J Anal Chem 345:589-591

95. Brotons JA, Olea-Serrano MF, Villalobos M, Pedraza V, Olea N (1995) Environ Health Prespect 103:608-612

96. Krishnan AV, Stathis P, Permuth SF, Tokes L, Fieldman D (1993) Endocrinology 132:2279-2286

97. Fromme H, Kuchler T, Otto T, Pilz K, Muller J, Wenzel A (2002) Water Res 36:1429-1438

98. Rudel RA, Melly SJ, Geno PW, Sun G, Brody JG (1998) Environ Sci Technol 32:861-869

99. Bolz U, Hagenmaier H, Korner W (2001) Environ Pollut 115:291-301

100. Staples CA, Dorn PB, Klecka GM, O’Block ST, Harris LR (1998) Chemosphere 36:2149_ 2173

101. Klecka GM, Gonsior SJ, West RJ, Goodwin PA, Markham DA (2001) Environ Toxicol Chem 20:2725-2735

102. Steinmetz R, Michner NA, Grant A, Allen DL, Bigsby RM, Ben-Johnathan N (1998) Endocrinology 139:2741-2747

103. Nagel SC, Vom Saal FS, Thayer CA, Dhar MG, Boechler M, Welshons WV (1997) Environ Health Prespect 105:70-76

104. Yokota H, Tsuruda Y, Maeda M, Shima Y, Tadokoro H, Nakazono A, Honjo T, Kobayasji K (2000) Environ Toxicol Chem 19:1925-1930

105. Braun P, Moeder M, Schrader S, Popp P, Kuschk P, Engewald W (2003) J Chromatogr A 988:41-51

106. Brossa L, Pocurull E, Borrull F, Marce RM (2002) Chromatographia 56:573-576

107. Varelis P, Balafas D (2000) J Chromatogr A 883:163

108. Sajiki J, Takahashi J, Yonekubo J (1999) J Chromatogr B 736:255-261

109. Inoue K, Wada M, Higuchi T, Oshio S, Umeda T, Yoshimura Y, Nakazawa H (2002) J

Chromatogr B Anal Technol Biomed Life Sci 773:97-102

110. DeMeulenaer B, Baert K, Lanckriet H, VanHoed V, Huyghebaert A (2002) J Agric Food Chem 50:5273-5282

111. Zhao MP, Li YZ, Guo ZQ, Zhang XX, Chang WB (2002) Talanta 57:1205-1210

112. Zhao M, Liu Y, Li Y, Zhang X, Chang W (2003) J Chromatogr B 783:401-410 
113. Ohkuma H, Abe K, Ito M, Kokado A, Kambegawa A, Maeda MU (2002) Analyst 127:9397

114. Kodaira T, Kato I, Li J, Mochizuki T, Hoshino M, Usuki Y, Oguri H, Yanaihara N (2000) Biomed Res 21:117-121

115. Ecobichon DJ, MacKenzie DO (1974) Res Commun Chem Pathol Pharmacol 9:85-95

116. Gerhard I, Runnebaum B (1992) Zent bl Gynakol 114:593-602

117. Ness D, Schantz S, Moshteghian J, Hansen L (1993) Toxicol Lett 68:311-323

118. Fiedler H, Hoff J, Tolls J, Mertens A, Gruber A, Hutzinger O (1994) Organohalogen Compd 15:199

119. McKinney JD, Waller CL (1994) Environ Sci Technol 102:290-297

120. Luster MI, Albro PW, Chae K, Chaudhary SK, Lawson LD, Corbett JT, McKinney JD (1979) Toxicol Appl Pharmacol 50:147-155

121. Newsome WH, Shields JB (1981) Int J Environ Anal Chem 10:295-304

122. Diaz-Ferrero J, Rodriguez-Larena MC, Comellas L, Jimenez B (1997) Trends Anal Chem 16:563-573

123. Sisak M, Franek M, Hruska K (1995) Anal Chim Acta 311: 415-422

124. Knopp D (1995) Anal Chim Acta 311:383-392

125. Mapes JP, McKenzie K, Stewart TN, Studabaker WB, Manning WB, Friedman SB (1993)

Bull Environ Contam Toxicol 50:219-225

126. Harrison RO, Melnychuk N (1995) Int J Environ Anal Chem 59:179-185

127. Franek M, Hruska K, Sisak M, Diblikova I (1992) J Agric Food Chem 40:1559-1565

128. Goon DJW, Nagasawa HT, Keyler DE, Ross CA, Pentel PR (1994) Bioconj Chem 5:418422

129. Johnson JC, Van Emon JM (1996) Anal Chem 68:162-169

130. Lawruk TS, Lachman CE, Jourdan SW, Fleeker JR, Hayes MC, Herzog DP, Rubio FM (1996) Environ Sci Technol 30:695-700

131. Chiu YW, Carlson RE, Marcus KL, Karu AE (1995) Anal Chem 67:3829-3839

132. Concejero MA, Galve R, Herradon B, Gonzalez MJ, de Frutos M (2001) Anal Chem 73:3119-3125

133. Kim IS, Setford SJ, Saini S (2000) Anal Chim Acta 422: 167-177

134. McGregor DB, Partensky C, Wilbourn J, Rice JM (1998) Environ Health Perspect 106:755-760

135. Grassman JA, Masten SA, Walker NJ, Lucier GW (1998) Environ Health Perspect 106:761-775

136. Behnisch PA, Hosoe K, Sakai S-i (2001) Environ Int 27:413-439

137. Harrison RO, Eduljee GH (1999) Sci Total Environ 239:1-18

138. Albro PW, Luster MI, Chae K, Chaudhary SK, Clark G, Lawson LD, Corbett JT, McKinney JD (1979) Toxicol Appl Pharmacol 50:137-146

139. Sherry JP, ApSimon JW, Collier TL, Albro PW (1990) Chemosphere 20:1409-1416

140. Kennel SJ, Jason C, Albro PW, Mason G, Safe SH (1986) Toxicol Appl Pharmacol $82: 256-263$

141. Stanker LH, Watkins B, Rogers N, Vanderlaan M (1987) Toxicology 45:229-243

142. Stanker LH, Watkins B, Vanderlaan M (1987) Chemosphere 16:1635-1639

143. Watkins B, Stanker LH, Vanderlaan M (1989) Chemosphere 19:267-270

144. Harrison RO, Carlson RE (1997) Chemosphere 34:915-928

145. Harrison RO, Carlson RE (1998) Organohalogen Compd 35:43-46

146. Harrison RO, Carlson RE, Shirkhan H (1995) Organohalogen Compd 23:187-192

147. Li W, Zu WZ, Barbara RB, Scrhamm KW, Kettrup A (1999) Chemosphere 38:3313-3318

148. Langley MN, Chopra RK, Creaser CS, Taylor RJK, Rose MD (1992) Food Agric Immunol $4: 143-152$

149. Gilman SD, Sanborn JR, Gee SJ, Denison MS, Stanker LH, Jones AD, Hammock BD (1995) Organohalogen Compd 23:231-235

150. Sugawara Y, Gee SJ, Sanborn JR, Hammock BD (1998) Anal Chem 70:1092-1099

151. Shan G, Leeman WR, Gee SJ, Sanborn JR, Jones AD, Chang DPY, Hammock BD (2001)

Anal Chim Acta 444:169-178 
152. Shelver WL, Huwe JK, Stanker LH, Patterson DG, Turner WE (2000) Organohalogen Compd 45:33-36

153. Shelver WL, Larsen GL, Huwe JK (1998) J Chromatogr B 705:261-268

154. Shelver WL, Shan G, Gee SJ, Stanker LH, Hammock BD (2002) Anal Chim Acta 457:199-209 